12 Evans A S. Causation and disease: the Henle-Koch postulates revisited. Yale f Biol 1976; 49: 175-95.

3 Cohen B J, Buckley M M. The prevalence of antibody to human parvovirus B19 in England and Wales. F Med Microbiol 1988; 25: 151-3.

14 Cohen B J, Buckley M M, Clewley J P, Jones V E, Puttick A H, Jacoby $\mathrm{R}$ K. Human parvovirus infection in early rheumatoid and inflammatory arthritis. Ann Rheum Dis 1986; 45: 832-8.

15 Lefrere J J, Meyer O, Menkes C J, Beaulieu M J, Courouce A M. Human parvovirus and rheumatoid arthritis. Lancet 1985; i: 982 .

16 Clewley J P. Polymerase chain reaction assay of parvovirus B19 DNA in clinical specimens. f Clin Microbiol 1989; 27: 2647-51.
17 Foto F, Saag K G, Scharosch I J, Howard E J, Naides S J. Parvovirus B19-specific DNA in bone marrow from B19 arthropathy patients: evidence for B19 virus persistence. F Infect Dis 1993; 167: 744-8.

18 Saal J G, Steile M, Einsele H, Muller C A, Fritz P, Zacker J. Persistence of B19 parvovirus in synovial membranes of patients with rheumatoid arthritis. Rheumatol Int 1992; 12: 147-51.

19 Gray J J, Cohen B J, Desselberger U. Detection of human parvovirus B19-specific IgM and IgG antibodies using a recombinant viral VPI Bl antigen expressed in insect cells and estimation of time of infection by

\title{
New questions about the muscular dystrophies
}

Neurologists, being interested in locating lesions in the nervous system, tend to think of muscles as organs, each with its unique nerve supply, rather than of muscle as a tissue. The rather consistent selective patterns of muscle wasting and hypertrophy which characterise each of the muscular dystrophies disappointingly still defy explanation and have to be learned by rote. Until very recently, diagnosis of the many types of muscular dystrophy has been based wholly on recognising these patterns, together with information on the onset and progression of symptoms, the serum creatine kinase activity and the family history. Even the histology in most types is consistent rather than diagnostic, and is useful mainly to exclude other quite different disorders. Since 1987, when deletions of the Duchenne gene and dystrophin assays were first used in diagnosis, this situation has begun to change and in the last few months of 1994 the point was reached when most of the common types of muscular dystrophy could be diagnosed by tests of genes or their products. The table summarises some of this new information.

Rheumatologists may encounter these disorders mainly when patients present with pain or contractures. Such symptoms tend to be local and may divert attention from widespread muscle wasting and weakness, so slowly progressive that the patient may be quite unaware of them. The most useful diagnostic instruments in this situation are the corridor and the staircase; if walking looks normal, running may bring out an obvious abnormality of gait. If watching the patient in action shows that there is a problem, detailed muscle examination will go a long way towards identifying it.

\section{Pain}

Pain is not a common feature of most muscular dystrophies, apart from the mild aching after exercise that occurs in anyone with muscle weakness, and no muscular dystrophy (MD) causes pain in the absence of physical signs. Calf pain during and after exercise is much more frequent in Becker MD than in other types, and may be comparable in severity to that seen in glycogen storage diseases such as McArdle's disease. It is quite often the presenting feature in subjects between the ages of about 5 and 25 years. The calves in Becker MD are usually obviously hypertrophic while the quadriceps, brachioradialis, costal origin of pectoralis major, and the latissimus dorsi are selectively atrophied. This distribution is seen also in the more severe Duchenne $\mathrm{MD}$, but calf pain is not so frequent. Female carriers of the $\mathrm{X}$ linked gene for these two disorders sometimes manifest a mild degree of muscular dystrophy, and calf pain and hypertrophy are two quite frequent features in such women. In cases and manifesting carriers of Duchenne and Becker MD, the serum creatine kinase concentration is always considerably increased.

Pain is also common in facioscapulohumeral (FSH) MD, though not usually at the onset. This autosomal dominant disorder (figure) causes weakness of closure of the eyes and lips, winging and elevation of the scapulae on abduction of the arms, and selective wasting of biceps, triceps and tibialis anterior, but spares the muscles of the forearms and generally also the proximal muscles of the lower limbs. It varies greatly within families in onset and severity. Four of its peculiar features, though not by any means present in every case, are asymmetry of involvement; the occasional occurrence of subacute episodes of permanently increased weakness affecting one or more muscles, typically in the upper arm and typically after exercise or occurring on the dominant side; pain in affected muscles, rather constant but worse on movement; and inflammatory in addition to dystrophic changes in the muscle biopsy. These four features are not always seen together and they have so far eluded explanation. Other than in sometimes having infiltration by inflammatory cells, the myopathy of FSH does not resemble polymyositis. A subclinical retinal vasculopathy, akin to Coats' disease, is a feature of FSH MD, ${ }^{5}$ but there is no evidence

Diagnosis of the common types of muscular dystrophy by tests of genes or their products ${ }^{1-4}$

\begin{tabular}{|c|c|c|c|}
\hline Muscular dystrophy & Gene site & Detectable gene lesions & Gene product \\
\hline $\begin{array}{l}\text { Duchenne } \\
\text { Becker } \\
\text { Emery-Dreifuss } \\
\text { Severe autosomal recessive } \\
\text { MD childhood (SCARMD2) }\end{array}$ & $\begin{array}{l}\text { Xp21 } \\
\text { Xp21 } \\
\text { Xq28 } \\
17 q 12-21\end{array}$ & $\begin{array}{l}\text { Deletions in } 60 \% \text {, a few duplications } \\
\text { Deletions in } 80 \% \\
\text { Deletions or insertions } \\
\text { Some point mutations }\end{array}$ & $\begin{array}{l}\text { Dystrophin } \\
\text { Dystrophin } \\
\text { Emerin } \\
\text { Adhalin ( } 50 \mathrm{kDa} \text { DAG) }\end{array}$ \\
\hline $\begin{array}{l}\text { North African (SCARMD1) } \\
\text { Fukuyama } \\
\text { Congenital (some cases) } \\
\text { Facioscapulohumeral† } \\
\text { Myotonic dystrophy }\end{array}$ & $\begin{array}{l}13 \mathrm{q} 12 \\
9 \mathrm{q} 31-33 \\
6 \mathrm{q} 2 \\
4 \mathrm{q} 35 \\
19 \mathrm{q} 13.3\end{array}$ & $\begin{array}{l}\text { Not yet } \\
\text { Not yet } \\
\text { Not yet } \\
\text { Small DNA fragment (probe p13E-11) } \\
\text { Unstable triple repeat (CTG) sequence }\end{array}$ & $\begin{array}{l}\text { Unknown, but secondary } 50 \mathrm{kDa} \text { DAG deficiency } \\
\text { Possibly } 43 \mathrm{kDa} \mathrm{DAG} \\
\text { Merosin (laminin M) } \\
\text { Unknown } \\
\text { Predicted membrane protein kinase }\end{array}$ \\
\hline
\end{tabular}

DAG = Dystrophin associated glycoprotein. (†P E Jardine et al, British Paediatric Neurology Association, Cambridge, 1995.). 


\section{puorocharuce earueloctece}

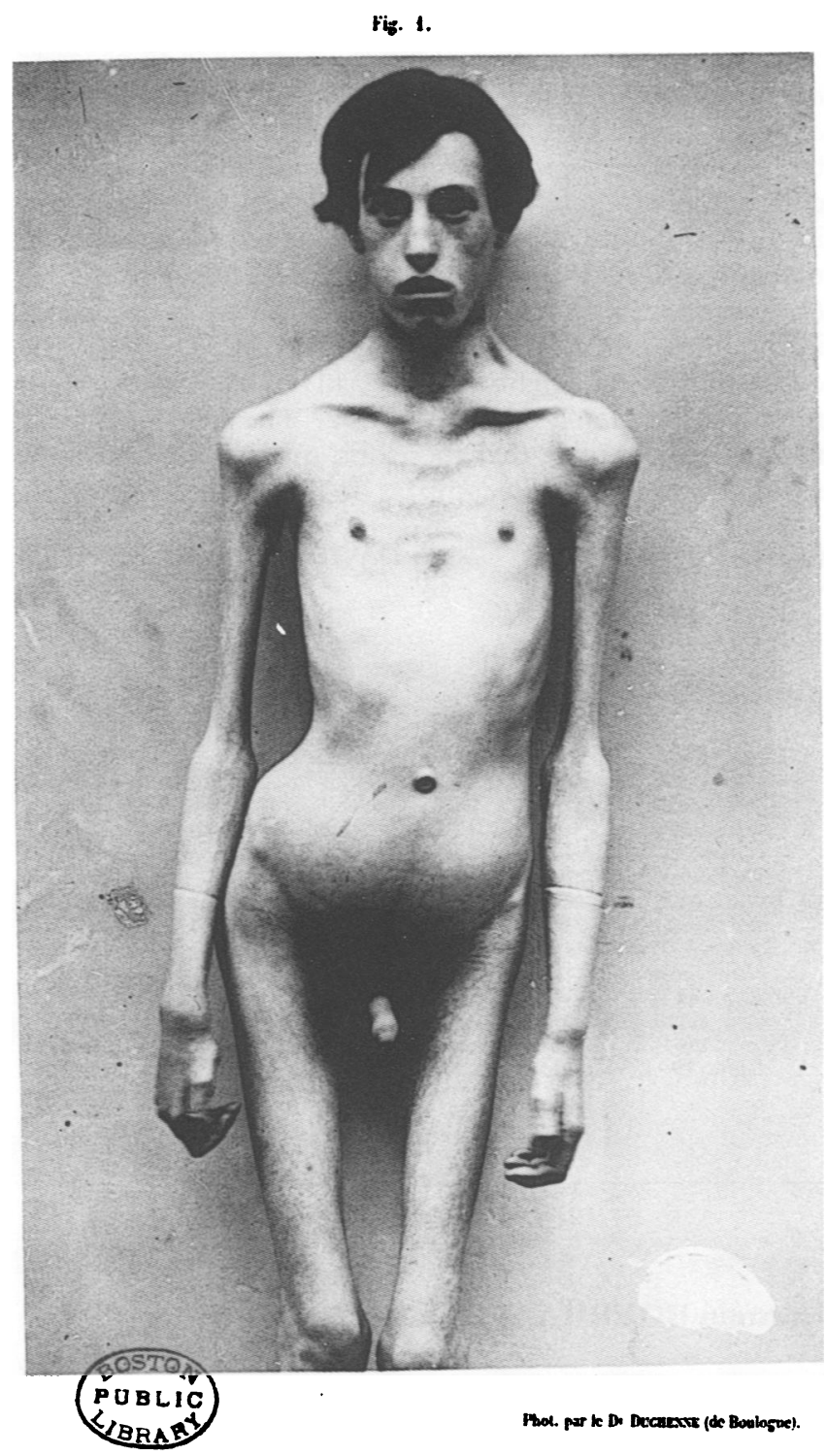

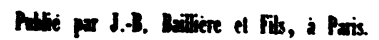

Photograph taken in the 1850s by Duchenne and published by him in his rare 1862 Album de Photographies Pathologiques, Balliere, Paris. Duchenne gave the history in detail and it is now clear that the patient suffered from Facioscapulohumeral Muscular Dystrophy 'first described' by Landouzy and Dejerine in 1884. The facial weakness, elevation of the scapulae and selective weakness of the upper arm muscles are clearly shown.

that the myopathy itself, or its inflammatory component, is related to vascular disease. The FSH gene is located at $4 \mathrm{q} 35$ and, as Fitzsimons ${ }^{6}$ has pointed out, there is a nucleotide sequence nearby, but not at the same site, which codes for a heat shock protein. De novo DNA fragments detected by probe p13E-11 at $4 \mathrm{q} 35$ (D4F104S1) cosegregate with the disease in families and the size of the fragment (14-38 kb) varies within families and correlates inversely with clinical severity (PE Jardine et al, British Paediatric Neurology Association, 1995). The deletion appears not to be within a functional gene, no gene product has been found, and it might influence the expression of nearby upstream genes, possibly including the HSP gene, though this very recent suggestion must be interpreted with caution. Steroids, but not (in my patients' experience) non-steroidal anti-inflammatory agents, improve the pain in the short term but are inappropriate for long term use; an effective regimen is much needed.
Nor is the proper use of rest (for inflammation) and exercise (generally helpful for maintaining muscle function in the other muscular dystrophies) understood. This is a potentially fruitful field for collaborative research.

\section{Contractures}

Muscles which are not effectively stretched, whether because of their increased tone or the weakness of their antagonists or external splinting, become shorter by losing sarcomeres. Such contractures are, in principle, reversible by long term stretching with orthoses. In muscular dystrophy there is the additional factor of perimysial and endomysial fibrosis which is believed to fix the shortened muscles and to make therapeutic, though not prophylactic, orthoses much less effective. Fibrosis is particularly prominent in the histology of the Duchenne and congenital types of $\mathrm{MD}$, and this is indeed reflected in the severity and rapidity of development of contractures. Two weeks in Majorca, away from his usual physiotherapy or without the night splints for his ankles, may be enough to permit irreversible contractures to occur in an eight year old with Duchenne MD. Their distribution, though rather uniform, seems simply to reflect the weakness of antagonists and, even more importantly, the habitual postures in bed or in the wheelchair. Their severity if it is attributable to fibrosis, is beginning to be explained, as we shall see below, by the newly discovered molecular pathology of a group of related types of MD.

A third type of muscular dystrophy is noted for its early and severe contractures, but in this case without obvious fibrosis. In Emery-Dreifuss MD, contractures develop in the first or second decade affecting the flexors of the elbows, ankle plantiflexors, and the paraspinal muscles, all before there is much muscle weakness. In severe cases there may be fixed retrocollis and extension of the spine, while hip flexion remains supple and power is only moderately impaired. In addition, cardiac conduction defects and sometimes cardiomyopathy may prove fatal and many patients need pacemakers at some point from the mid-teens onwards. This emphasises the importance of early recognition of the diagnosis when young male patients present with this pattern of contractures. The $\mathrm{X}$ linked gene, remote from that of Duchenne $M D$, has very recently been identified. ${ }^{1}$ It codes for a serine rich protein (named emerin) of 254 amino acids with features which suggest that it may, like dystrophin, be attached at one end (the C-terminus) to the inner surface of the cell membrane; it has points of similarity to proteins involved in vesicular transport.

\section{Molecular pathology}

In the past eight years, the genes for many of the muscular dystrophies have been located and sequenced. FSH MD and Emery-Dreifuss MD have been partially solved, and myotonic dystrophy is another important example, but these seem at this stage to be biochemically unrelated to other MDs. However, a group of clinically rather varied types are now known to comprise a family: Duchenne, Becker, one form of congenital $\mathrm{MD}$, and an autosomal recessive MD of childhood (SCARMD2). Each of these types has now been found to lack one of a group of structural proteins and glycoproteins associated with the muscle fibre membrane. Dystrophin, which is absent or virtually so in Duchenne $M D$ and reduced in abundance and molecular length in the milder allelic disorder, Becker $\mathrm{MD}$, is a $427 \mathrm{kDa}$ protein. In normal muscle it is attached at one end to the inner surface of the muscle fibre membrane and at the other to the contractile apparatus 
within. The membrane attachment sites seem to be composed of clusters of peg-like proteins and glycoproteins and the structure of several of these has been established. One of them, a $50 \mathrm{kDa}$ glycoprotein now named adhalin, has been shown to be deficient in SCARMD2. A report that a $43 \mathrm{kDa}$ glycoprotein was defective in the Fukuyama type of muscular dystrophy (rare outside Japan) has not been confirmed. Outside the muscle fibre membrane, the (glyco)proteins appear to be further attached to a web-like protein complex collectively known as laminin. Very recently one component, laminin-M or merosin, has been shown to be deficient in some cases of congenital muscular dystrophy. ${ }^{3}$

Interesting and satisfying though it is to be able to link the molecular pathology of these four classical types of $\mathrm{MD}$, there are many remaining puzzles to be solved. Duchenne and severe autosomal recessive $M D$ are clinically very similar, though with subtle differences in the pattern of affected muscles; also, Duchenne MD affects heart and brain, unlike SCARMD. There is another clinically similar genetic variant, SCARMD1, found throughout North Africa, the gene for which is located at 13q12. This is a prime candidate for a defect in one of the unattributed glycoproteins in the membrane complex described above. What of the many milder autosomal recessive and dominant forms of proximal $\mathrm{MD}$, formerly classified together under the term 'limb girdle MD'? Genes for three of these have been approximately located on chromosomes $2 \mathrm{p}, 5 \mathrm{q}$, and $15 \mathrm{q}$, but no gene products are yet known. Other limb girdle MDs are linked to none of these gene sites; might some such cases prove to be milder allelic forms of the protein defects already discovered? This question is likely to be answered, at least in part, in the next few months. Why should dystrophin deficiency, even when severe, cause clinical weakness to develop only after a period of relatively normal function and then to progress relentlessly, whereas merosin deficiency causes severe congenital weakness which thereafter remains fairly stable but with later progressive contractures? Can these contractures be related to the endomysial fibrosis, or this in turn to the missing merosin on the external surface of the muscle fibres? Why should the $43 \mathrm{kDa}$ DAG deficiency (if confirmed) cause severe mental handicap and epilepsy in addition to $M D$ (in Fukuyama $M D$ ), while the deficiency of the neighbouring $50 \mathrm{kDa}$ DAG spares brain function completely in SCARMD2? The field of muscle research is fortunate that these and many other questions seem now to fall within compass of 'the art of the soluble'.

Children's Department,

Newcastle General Hospital,

DAVID GARDNER-MEDWIN

Newcastle upon Tyne NE4 6BE

United Kingdom

1 Bione S, Maestrini E, Rivella S, et al. Identification of a novel X-linked gene responsible for Emery-Dreifuss muscular dystrophy. Nature Genetics 1994; 8: 323-7.

2 Gardner-Medwin D, Walton J. The muscular dystrophies. In: Walton J, Karpati G, Hilton-Jones D, eds. Disorders of voluntary muscle, 6 th edn, ch 14. Edinburgh: Churchill Livingstone, 1994.

3 Tome F M S, Evangelista T, Leclerc A, et al. Congenital muscular dystrophy with merosin deficiency. CR Acad Sci III 1994; 317: 351-7.

4 [Kaplan J C, Servidei S, eds]. Neuromuscular disorders: Gene location. Neuromuscular Disorders 1995; 5 (Appendix): I-VII.

5 Fitzsimons R B, Gurwin E B, Bird A C. Retinal vascular abnormalities in facioscapulohumeral muscular dystrophy. Brain 1987; 110: 631-48.

6 Fitzsimons R B. Facioscapulohumeral dystrophy: the role of inflammation. Lancet 1994; 344: 902-3.

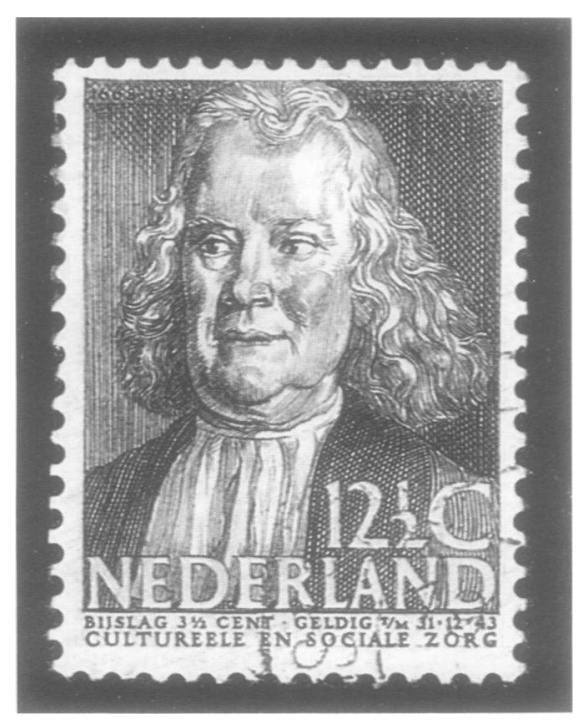

\section{Herman BOERHAAVE (1668-1738)}

Herman BOERHAAVE (the 'Batavian Hippocrates') was the greatest doctor in the Western world during the first half of the 18th century. Originally intending to go into the ministry, he eventually embarked on and pursued a scientific career. In his prime he had three separate professorships in botany, chemistry, and clinical medicine-in each of which fields he was a leading authority. Though he made no new discoveries and did no research as we see it, he was an excellent clinician. His energy, magnetism, interest, and patience led to innovations and bedside teaching in hospital care. In his writings, his Institutioneus Medicinae (1708) dealt with physiology, pathology, diagnostics, and therapy, while the Aphorisms were mainly clinical.

$\mathrm{He}$ combined observation and reason as the basis of medical science. In a spirit of Simplex Sigilum veri ('simplicity is the mask of the genuine') his students founded medical facilities in several cities in Europe.

Because of increasing illness, including gouty attacks, he had to restrict his activities from 1722 until his death. He had a favourite remedy - a form of passive exercise 'friction' (rubbing by means of a dry towel, or massage). $\mathrm{He}$ also differentiated gout from other rheumatic diseases.

$\mathrm{He}$ is commemorated on stamps of the Netherlands. 